\title{
Which is Safer to Avoid an Increase in ICP After Endotracheal Suctioning in Severe Head Injury: Intravenous or Endotracheal Lidocaine?
}

\author{
Fernanda A. Rodrigues ${ }^{\mathrm{a}}$, Carolina Kosour ${ }^{\mathrm{a}}$, Luciana Castilho de Figueiredo ${ }^{\mathrm{a}}$, Marcos M. Moreira ${ }^{\mathrm{a}}$, \\ Ana Paula D. C. Gasparotto ${ }^{\mathrm{a}}$, Desanka Dragosavac ${ }^{\mathrm{a}}$, Bruna Tuan ${ }^{\mathrm{b}}$, Patricia Moriel, \\ Luiz Claudio Martins ${ }^{\mathrm{a}}$, Antonio L. Eiras Falcao ${ }^{\mathrm{a}, \mathrm{c}}$
}

\begin{abstract}
Background: In patients with severe head injury, endotracheal suctioning (ES) is a potentially unsafe procedure, because it can increase intracranial pressure (ICP) and decrease cerebral perfusion pressure (CPP). Lidocaine has been shown to directly blunt ICP rises before ES, although it is not known whether the efficacy of lidocaine given endotracheally is comparable with that intravenously. The purpose of this study was evaluated the effects of ES on ICP with or without the use of lidocaine given endotracheally or intravenously in head trauma.
\end{abstract}

Methods: Twenty patients admitted to the intensive care unit having traumatic brain injury with Glasgow Coma Scale $\leq 8$ were evaluated. Patients were randomly given $1.5 \mathrm{mg} / \mathrm{kg}$ of $2 \%$ lidocaine intravenously (Group 1), $1 \mathrm{mg} / \mathrm{kg}$ of $2 \%$ lidocaine endotracheally (Group 2) or did not receive lidocaine (Group 3) prior to ES. The ICP, mean arterial pressure, heart rate and CPP were monitored continuously and were recorded prior and immediately after ES.

Results: There was no significant increase in ICP after ES in group $1(\mathrm{P}=0.56)$ and group $2(\mathrm{P}=0.06)$ patients. However, the ICP increased after ES in group 3 patients $(\mathrm{P}=0.0002)$.

Conclusions: Our findings suggest that the administration of lidocaine endotracheally or intravenously before ES effectively prevents the ICP increase and CPP reduction in severe head trauma. Aiming for patient safety we propose the use of endotracheal lidocaine because intravenous drugs have a heightened risk of causing significant patient harm when used in error and preventable adverse drug events, are a prominent quality and cost issue in healthcare.

\footnotetext{
Manuscript accepted for publication April 24, 2013

${ }^{a}$ Department of Surgery, School of Medical Sciences, State University of Campinas (UNICAMP), Brazil

bshool of Medical Sciences, State University of Campinas (UNICAMP), Brazil

${ }^{\mathrm{c} C}$ Corresponding author: Antonio L. Eiras Falcao, Hospital de Clinicas, Universidade Estadual de Campinas (Unicamp) Rua Zeferino

Vaz- Cidade Universitaria- Campinas- Sao Paulo, Brazil.

Email: falcao@unicamp.br
}

doi: http://dx.doi.org/10.4021/jnr201w
Keywords: Endotracheal suctioning; Lidocaine; Intracranial pressure; Cerebral perfusion; Brain injury; Patient safety

\section{Introduction}

Traumatic brain injury (TBI) is the leading cause of severe disability and death, and has a high economic cost to our society. Neurological damage from TBI does not occur only at the moment of impact, but evolves over the ensuing hours and days. Improved outcome results when these secondary, delayed insults, resulting in reduced cerebral perfusion to the injured brain, are prevented by avoiding an increase in intracranial pressure (ICP) and a decrease in cerebral perfusion pressure (CPP). This is reflected in the progressive and significant reduction in severe TBI mortality and morbidity and worldwide preoccupation in relation to prevention and best treatment [1-5].

In patients with severe head trauma, endotracheal suctioning (ES) is a necessary procedure during chest physiotherapy care. This procedure can result in unwanted airway and circulatory reflexes including short periods of apnea, cough, bronchospasm, variations in intrathoracic pressure, systemic hypertension, tachycardia, increased ICP and reduced CPP which may aggravate brain damage [6-10].

Lidocaine has long been used to modulate these responses. The administration of lidocaine has been given via different routes including intravenous (IV) injection and endotracheal tube (ETT) [8, 10-12].

Lidocaine-injected IV blunts the cough reflex in awake and anesthetized patients and evidence demonstrates that lidocaine sprayed down the ETT attenuates the airway-circulatory reflexes during emergency and extubation after general anesthesia [13-15]. These facts prompted us to reappraise the issue of endotracheal lidocaine instillation for blunting ES induced cerebral hemodynamic changes in patients undergoing intensive care after severe head trauma. However, no consensus has yet been reached in the literature in respect to its optimal route of administration $[11,16]$.

The purpose of this study was to evaluate the effects of ES on ICP, CPP with or without the use of endotracheal or 


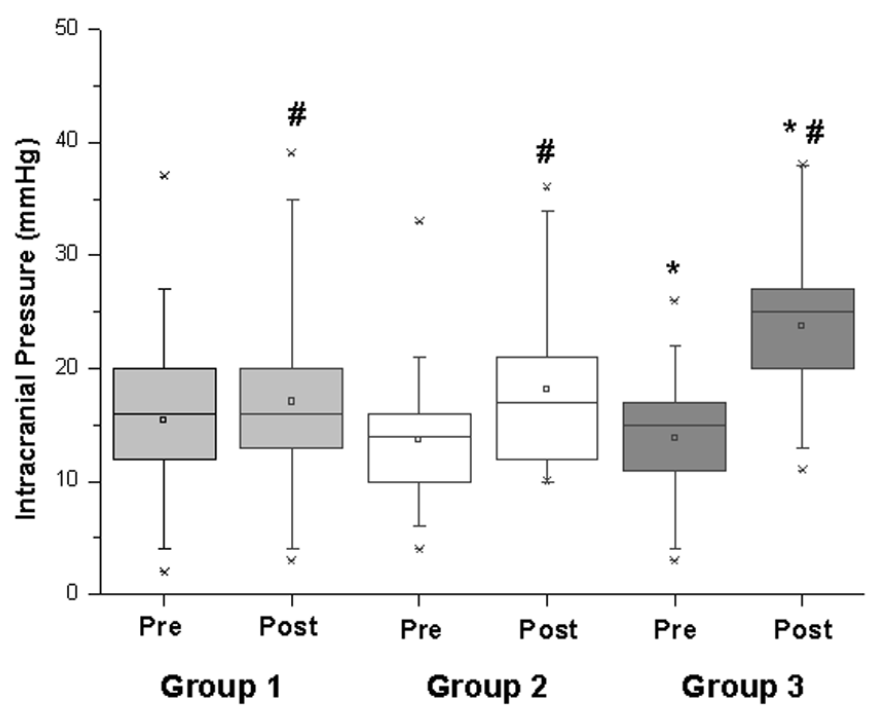

Figure 1. Intracranial Pressure pre and post Lidocaine administration. * $\mathrm{P}$ values $<0.05$ between Pre and Post moments; \# P values $<0.05$ comparison between groups.

intravenous lidocaine in severe head trauma patients.

\section{Materials and Methods}

This is a clinical control prospective study. With institutional approval, twenty patients, older than 18 years, admitted to the intensive care unit (ICU) at the Clinical Hospital of State University of Campinas having severe traumatic brain injury, with Glasgow Coma Scale of $\leq 8$ and intracranial pressure monitoring. Patients with the following criteria were excluded from the study: ICP $>20 \mathrm{mmHg}$ or $\mathrm{CPP}<60 \mathrm{mmHg}$ at baseline, $\mathrm{SaO}_{2}<94 \%, \mathrm{PaCO}_{2}<30 \mathrm{mmHg}$ and patients with clinically established brain death.

Patients were all intubated, mechanically ventilated, sedated and were maintained supine with the head elevated at $30^{\circ}$ and aligned with the trunk, according to protocols previously defined $[3,5]$. Mechanical ventilation was adjusted to maintain arterial oxygen saturation $\left(\mathrm{SaO}_{2}\right)$ above $94 \%$ and partial pressure of arterial carbon dioxide $\left(\mathrm{PaCO}_{2}\right)$ between 35 and $40 \mathrm{mmHg}$ with positive end-expiratory pressure (PEEP) of $5 \mathrm{~cm} \mathrm{H}_{2} \mathrm{O}$. Patients were pre-oxygenated (FiO2 $=1$ ) before ES to avoid oxygen desaturation and were not hyperventilated.

During the study phase the patients were stable and there was no concomitant administration of any treatment that would affect intracranial pressure such as mannitol or hypertonic saline. No muscle relaxants were used.

The patients were divided randomly into 3 groups $(\mathrm{n}=$ 20 for each). Group 1 received $1.5 \mathrm{mg} / \mathrm{kg}$ of $2 \%$ lidocaine intravenously; Group 2 patients received $1 \mathrm{mg} / \mathrm{kg}$ of $2 \%$ lidocaine endotracheally; Group 3 did not receive lidocaine. ES maneuver was performed by the same researcher 5 minutes after IVL and 3 minutes after ETL administration.

The ICP, mean arterial pressure (MAP), heart rate (HR) and CPP were recorded prior (Pre) and immediately after ES (Post). HR, MAP, arterial oxygen saturation $\left(\mathrm{SaO}_{2}\right)$, and ICP, were monitored continuously. The CPP was obtained according to the following calculation: $\mathrm{CPP}=\mathrm{MAP}$ - ICP. Tomographic findings were assessed according to Marshall's classification [17]. Plasma lidocaine levels were not measured.

\section{Statistical analysis}

Non-parametric analysis techniques were applied. The Mood test was used to find possible differences between groups and the Mann-Whitney test of two by two was applied to identify where these differences were. For comparison between times (Pre and Post), within the same variable, the Mann-Whitney test was also applied. P values $\leq 0.05$ were considered statistically significant.

\section{Results}

A total of 20 patients, with severe head trauma admitted to the intensive care unit, met entry criteria. Eighteen patients (90\%) were of the male sex and the patients' mean age was $28.5 \pm 10.4$.

Tomographic findings according to Marshall's classification [17] showed diffuse injury type II in 6 patients (30\%), diffuse injury type III in 6 patients $(30 \%)$, subdural hematoma in 5 patients (25\%) and epidural hematoma in $3(15 \%)$.

No statistically significant differences were found when 
Table 1. Hemodynamic Variables and Cerebral Perfusion Pressure During the Study Period

\begin{tabular}{|c|c|c|c|c|c|c|}
\hline & \multicolumn{2}{|c|}{$\begin{array}{c}\text { Group } 1(n=20) \\
\text { (Lidocaine intravenously) }\end{array}$} & \multicolumn{2}{|c|}{$\begin{array}{c}\text { Group 2 } \\
(\mathbf{n}=\mathbf{2 0}) \\
\text { (Lidocaine } \\
\text { Endotracheally) }\end{array}$} & \multicolumn{2}{|c|}{$\begin{array}{c}\text { Group } 3(n=20) \\
\text { (Without Lidocaine) }\end{array}$} \\
\hline & Pre & Post & Pre & Post & Pre & Post \\
\hline Heart Rate (bpm) & $91.0 \pm 13.9$ & $93.8 \pm 14.0$ & $92.9 \pm 15.7$ & $100.3 \pm 18.8$ & $96.3 \pm 20.4$ & $104.9 \pm 21.9$ \\
\hline Mean Arterial Pressure (mmHg) & $93.0 \pm 20.0$ & $100.8 \pm 19.8$ & $96.2 \pm 10.6$ & $97.2 \pm 10.7$ & $94.7 \pm 14.2$ & $97.3 \pm 14.0$ \\
\hline Cerebral Perfusion Pressure $(\mathrm{mmHg})$ & $76.5 \pm 19.2$ & $84.2 \pm 18.3$ & $82.5 \pm 12.3$ & $79.0 \pm 13.8$ & $80.8 \pm 16.6$ & $73.5 \pm 17.5$ \\
\hline
\end{tabular}

Average \pm standard deviation; no significant difference among groups and Pre e Post moments; bpm: beats per minute.

baseline (Pre) measurements of HR, MAP, ICP and CPP in the three treatment groups were compared.

Statistically, a significant difference was found in ICP when Pre and Post measurements in group $3(\mathrm{P}=0.0002)$ were compared as seen in Figure 1. When assessing the results of ICP at pre and post ES among the groups, statistically significant differences $(P=0.02)$ were found. The NL method was statistically different from the other two methods (ETL and EVL) for the variable ICP (Fig. 1).

No statistical difference was found among the studied groups in relation to the variables HR, MAP and CPP as well as Pre and Post ES (Table 1).

\section{Discussion}

Various forms of sensory stimulation (including laryngoscopy, tracheal intubation, and endotracheal suctioning) may cause marked increases in ICP and MAP $[11,18,19]$.

The major determinant of the magnitude of the ICP increase during endotracheal suctioning appears to be the transmission of cough-induced increase in intrathoracic pressure into the cerebral venous system resulting in a transient increase in cerebral venous pressure and intracranial volume. Head-injured patients with abnormal intracranial pressurevolume relationships may develop precipitous increase in ICP if cerebral venous pressure increases [6]. Therefore, the ability of a given drug to suppress the cough reflex appears to be more important in preventing intracranial hypertension than any effect exerted on the cerebral arterial system $[6,7$, $10,11,20,21]$.

Two main mechanisms, neuronal blockade of vagal reflex pathways and direct effects on smooth muscle cells, may explain the effect of lidocaine on bronchial reactivity [22-24]. Groeben et al [25] suggested in their study that the reflex suppression is the main mechanism to explain the protective effect of intravenous lidocaine in awake volunteers with bronchial hyper reactivity and showed that peak plasma concentrations following lidocaine inhalation were significantly lower than those under intravenous administration. Other studies showed that inhalation of lidocaine yields many airway concentrations with lower plasma concentration than intravenous administration [26-28].

Since the publication of Hamill et al [11], lidocaine has been recommended before ES in neurocritical patients and the procedure should be performed three minutes after ETL and 5 minutes after IVL. Based on good clinical results, in daily practice, we decided to keep this time interval before ES. A consistent dosage of $1.5 \mathrm{mg} / \mathrm{kg}$ IVL was administered across the six human studies. Nevertheless, ETL dosage varied across human studies from $1.5 \mathrm{~mL} / \mathrm{kg}$ to $4 \mathrm{~mL}$ of lidocaine $4 \%[6,11,13,20,21,29]$. In our study $1.5 \mathrm{mg} / \mathrm{kg}$ IVL was administered which was the same as Groeben et al [25] who obtained a plasma concentration of $2.4 \pm 0.15 \mu \mathrm{g} / \mathrm{mL}$. For ETL dosage in our study we used $1 \mathrm{mg} / \mathrm{kg}$ of lidocaine while Groeben et al [25] used $5 \mathrm{mg} / \mathrm{kg}$ and had a lidocaine plasma concentration of $1.5 \pm 0.14 \mu \mathrm{g} / \mathrm{mL}$, that suggests that the level of lidocaine in our patients' plasma was lower than $1.5 \mu \mathrm{g} / \mathrm{mL}$. There are conflicting views in studies regarding maximum safe doses of local anesthetic drugs [30-33]. There was direct correlation between pharmacological effect of lidocaine $[30,31]$ and blood concentration of lidocaine in arterial plasma at which symptoms of local anesthetic toxicity were evident ranging from 2.0 to $6.0 \mu \mathrm{g} / \mathrm{mL}$ [34]. Therefore, we suggest that ETL can be used as safely as IVL, as long as plasma levels of lidocaine are outside the range of toxicities.

As a result, Lidocaine has now become part of the therapeutic arsenal for patients with severe head trauma but there has been no consensus neither in our group nor in literature about which the ideal administration of standardized doses 
of lidocaine should be which motivated this research.

The pressure response to laryngoscopy and endotracheal intubation have been recognized and studied since 1951 [19]. However, in a study by Hamill et al (1981) the lack of efficacy of topically applied laryngotracheal lidocaine in preventing increased ICP, hypertension, and tachycardia after intubation was unexpected, particularly in view of its widespread clinical use [11].

In the present study, there were non-significant results of HR, MAP and CPP following ES in the three groups. These results can be explained by the intense sympathetic stimulation during the end ES maneuver which was probably blocked by sedation and analgesia, not only by lidocaine although some studies have concluded that lidocaine does not attenuate cardiovascular response [14, 15, 29, 35, 36]. Nevertheless, Hamaya et al reported that the sympathetic responses mediated by the tactile stimulation of the larynx, tracheal carina and bronchi were completely blocked by ETL and partially blocked by IVL [14].

In our results, we found statistically significant increase of ICP after ES in group 3. Although a decrease was not found in ICP after ES in group 1 and 2, our results suggests a better control of the ICP after ES with ETL or IVL, avoiding values of ICP greater than $20 \mathrm{mmHg}$. The findings were discussed by Grover et al [12] where it was observed that the prophylactic effect of IVL on a dose of $1.5 \mathrm{mg} / \mathrm{kg}$ resulted in a decrease in ICP, and recommended its routine use. In our previous practical and clinical analysis, we have noted clinical controversy surrounding administration of lidocaine before ES in patients with brain injury and we have observed that there is no guideline of safety and effectiveness of this practice, arousing controversy over the best route and doses with consequent limitations on the universal implementations. In our research, it was applied the literature recommended dosage that should be administered in the endotracheal tube or intravenously $[11,13]$. It was not our intention to compare or question the safety and effectiveness of different doses of lidocaine. It must be observed that our patients had no intracranial hypertension and for ethical reasons and based on current literature we had no group without lidocaine if patients was under increased ICP. Clearly, no acute deterioration was observed with any of the three regimens but, in theory, secondary brain injury caused by global or localized cerebral ischemia is certainly possible when CPP decreases followed by an increase in ICP that was avoided in lidocaine groups. Even 'safe' medications need to be administered with care [37]. It is important that the medical team play a significant role in critically evaluating the use of medication and procedures in the management of patients in critical states in special severe head injury.

\section{Conclusion}

According to our preliminary data from prospective pilot study, the use of lidocaine administered intravenously or endotracheally can prevent ICP changes during routine endotracheal suctioning by tube. Either endotracheal or intravenous lidocaine was completely successful in preventing a rise in ICP. Aiming for patient safety we propose the use of endotracheal lidocaine because ETL can be used as safely as IVL, as long as plasma levels of lidocaine are outside the range of toxicities and intravenous drugs have a heightened risk of causing significant patient harm when used in error and preventable adverse drug events, are a quality and cost issue in healthcare [37-39].

\section{References}

1. Farahvar A, Gerber LM, Chiu YL, Carney N, Hartl R, Ghajar J. Increased mortality in patients with severe traumatic brain injury treated without intracranial pressure monitoring. J Neurosurg. 2012;117(4):729-734.

2. Jiang JY. Head trauma in China. Injury http://dx.doi. org/10.1016/j.injury. 2012.08. 045.

3. Falcao AL, Dantas Filho VP, Sardinha LA, Quagliato EM, Dragosavac D, Araujo S, Terzi RG. Highlighting intracranial pressure monitoring in patients with severe acute brain trauma. Arq Neuropsiquiatr. 1995;53(3A):390-394.

4. Carney N, Lujan S, Dikmen S, Temkin N, Petroni G, Pridgeon J, Barber J, et al. Intracranial pressure monitoring in severe traumatic brain injury in latin america: process and methods for a multi-center randomized controlled trial. J Neurotrauma. 2012;29(11):2022-2029.

5. Bratton SL, Chestnut RM, Ghajar J, et al: Guidelines for the management of severe traumatic brain injury. J Neurotrauma 24:S01-106, 2007.

6. Robinson N, Clancy M. In patients with head injury undergoing rapid sequence intubation, does pretreatment with intravenous lignocaine/lidocaine lead to an improved neurological outcome? A review of the literature. Emerg Med J. 2001;18(6):453-457.

7. Fisher DM, Frewen T, Swedlow DB. Increase in intracranial pressure during suctioning--stimulation vs. rise in PaCO2. Anesthesiology. 1982;57(5):416-417.

8. Lev R, Rosen P. Prophylactic lidocaine use preintubation: a review. J Emerg Med. 1994;12(4):499-506.

9. Gemma M, Tommasino C, Cerri M, Giannotti A, Piazzi $\mathrm{B}$, Borghi T. Intracranial effects of endotracheal suctioning in the acute phase of head injury. J Neurosurg Anesthesiol. 2002;14(1):50-54.

10. Jee D, Park SY. Lidocaine sprayed down the endotracheal tube attenuates the airway-circulatory reflexes by local anesthesia during emergence and extubation. Anesth Analg. 2003;96(1):293-297, table of contents.

11. Hamill JF, Bedford RF, Weaver DC, Colohan AR. Lidocaine before endotracheal intubation: intravenous or 
laryngotracheal? Anesthesiology. 1981;55(5):578-581.

12. Grover VK, Reddy GM, Kak VK, Singh S. Intracranial pressure changes with different doses of lignocaine under general anaesthesia. Neurol India. 1999;47(2):118121.

13. Yano M, Nishiyama H, Yokota H, Kato K, Yamamoto Y, Otsuka T. Effect of lidocaine on ICP response to endotracheal suctioning. Anesthesiology. 1986;64(5):651-653.

14. Hamaya Y, Dohi S. Differences in cardiovascular response to airway stimulation at different sites and blockade of the responses by lidocaine. Anesthesiology. 2000;93(1):95-103.

15. Stoelting RK. Circulatory changes during direct laryngoscopy and tracheal intubation: influence of duration of laryngoscopy with or without prior lidocaine. Anesthesiology. 1977;47(4):381-384.

16. Bilotta F, Branca G, Lam A, Cuzzone V, Doronzio A, Rosa G. Endotracheal lidocaine in preventing endotracheal suctioning-induced changes in cerebral hemodynamics in patients with severe head trauma. Neurocrit Care. 2008;8(2):241-246.

17. Marshall LF, Marshall SB, Klauber MR et al A new classification of head injury based on computerized tomography. J. Neurosurg 75:S14-20, 1991.

18. Brucia JJ, Owen DC, Rudy EB. The effects of lidocaine on intracranial hypertension. J Neurosci Nurs. 1992;24(4):205-214.

19. Kraut RA. A comparison of intravenous and laryngotracheal lidocaine before endotracheal intubation. Anesth Prog. 1983;30(2):34-36.

20. Donegan MF, Bedford RF. Intravenously administered lidocaine prevents intracranial hypertension during endotracheal suctioning. Anesthesiology. 1980;52(6):516518.

21. Bedford RF, Persing JA, Pobereskin L, Butler A. Lidocaine or thiopental for rapid control of intracranial hypertension? Anesth Analg. 1980;59(6):435-437.

22. Weiss EB, Hargraves WA, Viswanath SG. The inhibitory action of lidocaine in anaphylaxis. Am Rev Respir Dis. 1978;117(5):859-869.

23. Kai T, Nishimura J, Kobayashi S, Takahashi S, Yoshitake J, Kanaide H. Effects of lidocaine on intracellular $\mathrm{Ca} 2+$ and tension in airway smooth muscle. Anesthesiology. 1993;78(5):954-965.

24. Szocik JF, Gardner CA, Webb RC. Inhibitory effects of bupivacaine and lidocaine on adrenergic neuroeffector junctions in rat tail artery. Anesthesiology. 1993;78(5):911-917.

25. Groeben H, Silvanus MT, Beste M, Peters J. Both intravenous and inhaled lidocaine attenuate reflex bronchoconstriction but at different plasma concentrations. Am J Respir Crit Care Med. 1999;159(2):530-535.

26. Patel RI, Peterson RG, Aldrete JA. Endotracheal com- pared with intravenous injection of $3 \mathrm{mg} / \mathrm{kg}$ of lignocaine. Measurement of arterial and venous levels. Anaesthesia. 1981;36(8):772-774.

27. Scott DB, Littlewood DG, Covino BG, Drummond GB. Plasma lignocaine concentrations following endotracheal spraying with an aerosol. Br J Anaesth. 1976;48(9):899-902.

28. Prengel AW, Lindner KH, Hahnel J, Ahnefeld FW. Endotracheal and endobronchial lidocaine administration: effects on plasma lidocaine concentration and blood gases. Crit Care Med. 1991;19(7):911-915.

29. Splinter WM. Intravenous lidocaine does not attenuate the haemodynamic response of children to laryngoscopy and tracheal intubation. Can J Anaesth. 1990;37(4 Pt 1):440-443.

30. Tucker GT. Pharmacokinetics of local anaesthetics. Br J Anaesth. 1986;58(7):717-731.

31. Benowitz NL, Meister W. Clinical pharmacokinetics of lignocaine. Clin Pharmacokinet. 1978;3(3):177-201.

32. Efthimiou J, Higenbottam T, Holt D, Cochrane GM. Plasma concentrations of lignocaine during fibreoptic bronchoscopy. Thorax. 1982;37(1):68-71.

33. Becker DE, Reed KL. Local anesthetics: review of pharmacological considerations. Anesth Prog. 2012;59(2):90-101; quiz 102-103.

34. Tucker GT, Mather LE. Clinical pharmacokinetics of local anaesthetics. Clin Pharmacokinet. 1979;4(4):241278.

35. Oczenski W, Krenn H, Dahaba AA, Binder M, El-Schahawi-Kienzl I, Jellinek H, Schwarz S, et al. Hemodynamic and catecholamine stress responses to insertion of the Combitube, laryngeal mask airway or tracheal intubation. Anesth Analg. 1999;88(6):1389-1394.

36. Youngberg JA, Graybar G, Hutchings D. Comparison of intravenous and topical lidocaine in attenuating the cardiovascular responses to endotracheal intubation. South Med J. 1983;76(9):1122-1124.

37. Lutwak N, Howland MA, Gambetta R, Dill C. Even 'safe' medications need to be administered with care. BMJ Case Rep. 2013;2013

38. Adapa RM, Mani V, Murray LJ, Degnan BA, Ercole A, Cadman B, Williams CE, et al. Errors during the preparation of drug infusions: a randomized controlled trial. Br J Anaesth. 2012;109(5):729-734.

39. Betsy J. Lahue, MPH; Bruce S. Pyenson, FSA, MAAA; Kosuke Iwasaki, FIAJ, MAAA; Helen E. Blumen, MD, MBA; Susan Forray, FCAS, MAAA; Jeffrey M. Rothschild, MD, MPH. National burden of preventable adverse drug event associated with inpatient injectable medication : healthcare and medical professional liability costs. http://www.ahdbonline.com/feature/nationalburden-preventable-adverse-drug-events-associatedinpatient-injectable-medication. 